\title{
FACTORS CONTRIBUTING TO COVID-19 VACCINATION HESITANCY IN THE PUNJAB
}

\author{
Shahzad Farid \\ Incharge, Department of Anthropology \\ University of Okara \\ s.farid@uo.edu.pk \\ Sajjad Hussain \\ International Islamic University, Islamabad \\ Rashid Maqbool \\ University of Okara
}

\begin{abstract}
The study aimed to explore the factors contributing to the COVID-19 vaccination hesitancy in the Punjab. The study was conducted in South Punjab by selecting 450 respondents who were approached using simple random sampling and interviewed using face to face interview schedule. The study explored that the percentage of vaccinated males is higher than females. It was also found that most of the respondents disagreed with COVID-19 hesitancy statements. The analysis revealed that vaccinated respondents have medium level hesitancy and their main source of information about the pandemic was newspapers. However, the respondents who are not vaccinated have prominent level of vaccination hesitancy and their main source of information about the pandemic is television/news. The study suggested an extended and rigorous campaign on national level television to reduce the impact of the unconfirmed information about COVID-19.
\end{abstract}

Keywords: COVID-19, Vaccination, Pandemic, Hesitancy

\section{INTRODUCTION}

Considering the increasing global rate of COVID-19 confirmed cases and deaths, different vaccinations were introduced which retained some doubts on its effectiveness such as the adverse effects of the vaccination (Eguia et al., 2021; Saied et al., 2021). However, the educated parents desired to vaccinate themselves and their children (Rhodes et al., 2020). Similarly, medical students are also willing to vaccinate themselves (Lucia, Kelekar, \& Afonso, 2020). Some of the studies (e.g., (Arce et al., 2021) also explored that vaccination acceptance is higher among low- and middle-income countries such as Asia, Africa and South America.

Despite the governmental instructions and strict imposition to vaccinate, the acceptance of COVID-19 vaccination considerably lower around the globe due to the prevalent unconfirmed information such as the pandemic itself is a part of hidden global agenda (Holeva et al., 2021). The role of conspiracy theories is not negligible because they reduce the trust on government, social distancing and, generally, adoption of preventative measure against the virus (Pummerer, 2020). Some studies (e.g., Guillon \& Kergall, 2021) also explored that vaccination is a greater risk to health.

Pakistan is also suffering from such conspiracy theories including the cultural beliefs which proved to be the strong barriers of vaccination. The most propagated theories in the country at government level stated that COVID-19 pandemic is a grand illusion and conspiracy against Muslims (Khan et al., 2020). The role of religious beliefs and media are also significant in spread of such unconfirmed information about the vaccination. The Pakistani media, especially social and print media, shared news about two years life span after vaccination, which was latterly denounced. The clerics used to divulge that the pandemic is an anger of Allah, and it cannot affect Muslims because we used to wash our apparent body parts five times a day. On the other hand, the unequal access to the vaccination is also a barrier to vaccination (Perveen et al., 2021). 
The present study aimed to explore the reality on ground about the COVID-19 vaccination hesitancy. The study also explored the perception of masses about the pandemic as well as the prevalence of the preventive measures against the pandemic.

\section{METHODOLOGY}

The study aimed to explore factors contributing to the COVID-19 vaccination hesitancy. The study used the quantitative research approach. The study selected 450 respondents from South Punjab and approached these respondents using simple random sampling technique. The study used face to face interview schedule for data collection. The tool of the study comprised two parts.

First, the demographic information of the respondents including the COVID-19 vaccination status was collected. Second, the vaccination hesitancy was measured on five points likert scale ranged from $1=$ strongly agree to $5=$ strongly disagree. This part was designed considering the indigenous / cultural rumors about the vaccination such as one of the statement reads, "It can make me impotent."

ANALYSIS AND RESULTS

Table No. 1 Demographic and COVID-19 related information of respondents

\begin{tabular}{|c|c|c|}
\hline Variable & Frequency & Percentage \\
\hline \multicolumn{3}{|l|}{ Gender } \\
\hline Female & 130 & 28.9 \\
\hline Male & 320 & 71.1 \\
\hline \multicolumn{3}{|l|}{ Living Area } \\
\hline Rural & 233 & 51.8 \\
\hline Urban & 217 & 48.2 \\
\hline \multicolumn{3}{|l|}{ Family System } \\
\hline Nuclear Family & 176 & 39.1 \\
\hline Joint Family & 274 & 60.9 \\
\hline \multicolumn{3}{|l|}{ Education } \\
\hline Illiterate & 2 & .4 \\
\hline Primary & 21 & 4.7 \\
\hline Middle & 34 & 7.6 \\
\hline Matric & 37 & 8.2 \\
\hline Intermediate & 48 & 10.7 \\
\hline Graduation & 85 & 18.9 \\
\hline Masters & 128 & 28.4 \\
\hline M.Phil. & 76 & 16.9 \\
\hline Ph.D & 19 & 4.2 \\
\hline \multicolumn{3}{|c|}{ Confirmed Case of COVID-19 } \\
\hline No & 292 & 64.9 \\
\hline Yes & 158 & 35.1 \\
\hline \multicolumn{3}{|l|}{ Vaccinated } \\
\hline No & 236 & 52.4 \\
\hline Yes & 214 & 47.6 \\
\hline \multicolumn{3}{|c|}{ Source of Information about COVID-19 } \\
\hline Television / news & 275 & 61.1 \\
\hline Newspaper & 131 & 29.1 \\
\hline Friends & 34 & 7.6 \\
\hline Family & 10 & 2.2 \\
\hline Total & 450 & 100 \\
\hline
\end{tabular}

Table 1 showed that the male respondents (71.1\%) participated in the study more than female (28.9\%). The cross tabulation also showed that the percentage of vaccinated male respondents $(67.3 \%)$ is higher than females (32.7\%). The participation of the rural respondents is almost $4 \%$ higher than the rural areas. It was also found that the prevalence of vaccinated respondents in urban 
areas is $90 \%$ higher than urban areas. The respondents from the joint family system participated nearly $50 \%$ higher than the respondents from nuclear family system. The table also showed that most of the respondents have master level education (28.4\%), but the percentage of illiterate and Ph.D. is very minimal ( $0.4 \%$ and $4.23 \%$, respectively). Interestingly, the percentage of the confirmed COVID19 cases $(35.1 \%)$ is almost $10 \%$ lower than the respondents who are vaccinated (47.6\%). It was also explored that the major source of information about the COVID-19 pandemic in South Punjab is television or news. The second major source of information is newspaper. However, the information about the pandemic has been rarely shared among friends and family (7.6\% and $2.2 \%$ respectively).

Table No. 2 COVID-19 vaccination hesitancy

\begin{tabular}{|c|c|c|c|c|c|}
\hline Items & SA & $\mathbf{A}$ & UD & D & SD \\
\hline It can make me impotent & $31(6.9)$ & $88(19.6)$ & $104(23.1)$ & $155(34.4)$ & $72(16.0)$ \\
\hline $\begin{array}{l}\text { I am afraid, it shall be scarce and I } \\
\text { have to purchase it costly }\end{array}$ & $60(13.3)$ & $114(25.3)$ & $111(24.7)$ & $126(28)$ & $39(8.7)$ \\
\hline $\begin{array}{l}\text { The rich people can control my } \\
\text { mind through this vaccination }\end{array}$ & $19(4.2)$ & $77(17.1)$ & $139(30.9)$ & $135(30)$ & $80(17.8)$ \\
\hline $\begin{array}{l}\text { It contains pig elements that Islam } \\
\text { do not allow to inject }\end{array}$ & $25(5.6)$ & $71(15.8)$ & $128(28.4)$ & $142(31.6)$ & $84(18.7)$ \\
\hline $\begin{array}{l}\text { I shall die after two years of } \\
\text { getting COVID-19 vaccine }\end{array}$ & $24(5.3)$ & $77(17.1)$ & $122(27.1)$ & $143(31.8)$ & $84(18.7)$ \\
\hline $\begin{array}{l}\text { I avoid COVID-19 vaccine } \\
\text { because medicine of seasonal flue } \\
\text { can cure it }\end{array}$ & $38(8.4)$ & $44(9.8)$ & $78(17.3)$ & $165(36.7)$ & $125(27.8)$ \\
\hline $\begin{array}{l}\text { There is a defined day of death, If } \\
\text { I am to live, I can live without } \\
\text { vaccine }\end{array}$ & $22(4.9)$ & $53(11.8)$ & $89(19.8)$ & $167(37.1)$ & $119(26.4)$ \\
\hline
\end{tabular}

Note: $\mathrm{SA}=$ Strongly Agree, $\mathrm{A}=$ Agree, $\mathrm{UD}=$ Undecided, $\mathrm{D}=$ Disagree, $\mathrm{SD}=$ Strongly disagree.

Table 2 comprised frequency and percentage distribution of the items of COVID-19 vaccination hesitancy questionnaire. The table showed that $34.4 \%$ of the respondents disagreed that the vaccination could cause impotency. However, most of the respondents (Strongly Agree $=13.3 \%$ and Agree $=25.3 \%$ ) were of the view that in near future, the vaccination would be costly and they would not be in financial position to purchase it because they have to vaccinate themselves again. The conspiracy theory favor of accepting Islam prohibited using medicine containing pig elements (Disagree $=31.6 \%$ and Strongly Disagree $=18.7 \%$ ). The table also showed that the overall percentages of disagreement are higher than the percentages of agreeing with the hesitancy statements.

Figure 1 showed the graphical results of the Multiple Correspondence Analysis (MCA) comprising the COVID-19 vaccination hesitancy index, status of vaccination and the source of information about the COVID-19 pandemic. The hesitancy index was constructed by computing all the scores of the scale to explore the interval for three level categories i.e., Low, Medium and High Hesitancy. The index scores were inverse: the lower values interval (i.e., 7 to 18) were given the higher hesitancy because the coding of the five points likert scales rated high value to the disagreement with the hesitancy statements. 


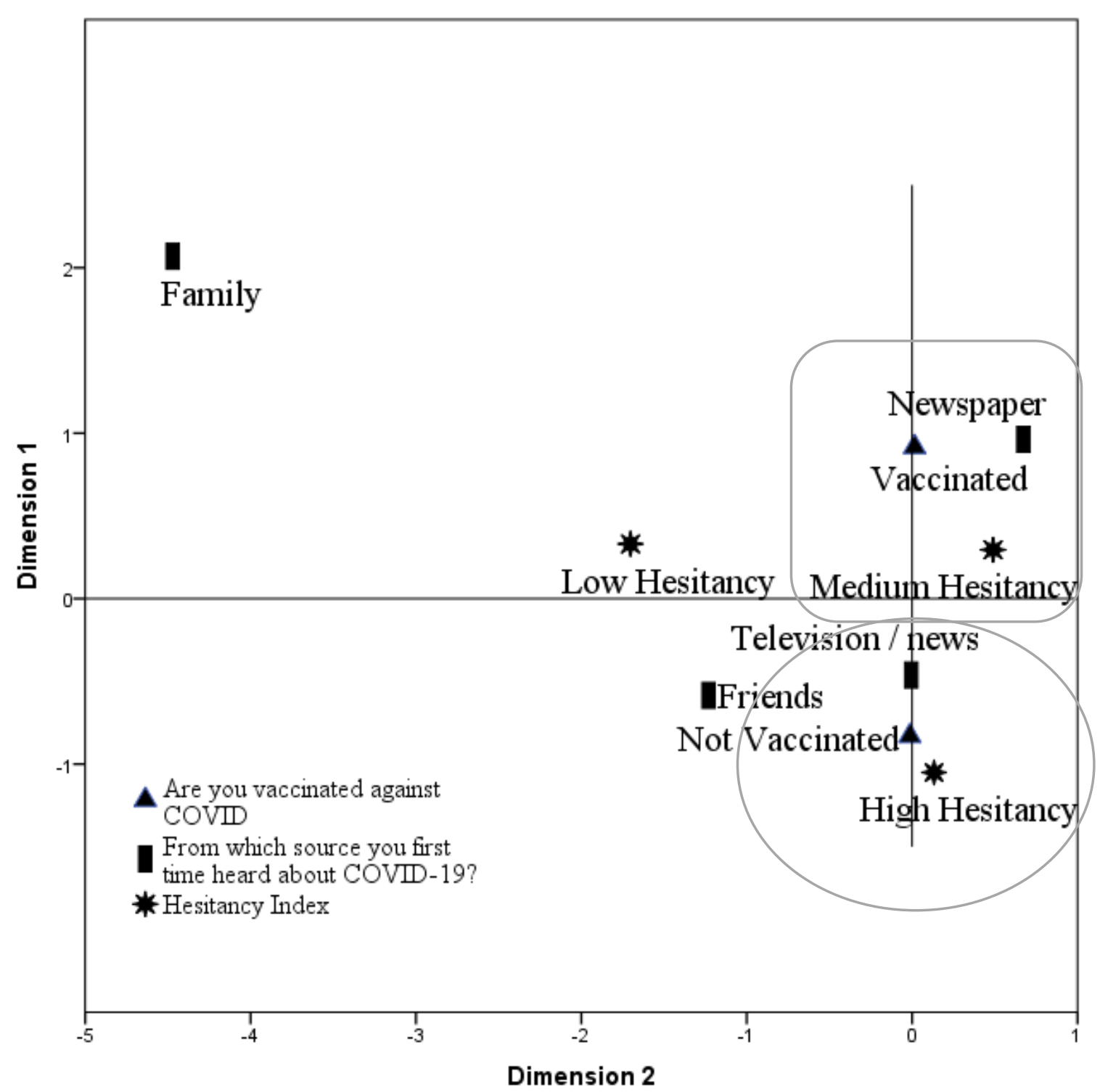

Figure 1. Multiple Correspondence Analysis of COVID-19 Vaccination Hesitancy, Vaccination Status and Source of Information. Dimension 1: Cronbach Alpha = 0.564, Eigenvalue $=1.6, \%$ of Variance $=53.42$. Dimension 2 : Cronbach Alpha $=0.411$, Eigenvalue $=1.38, \%$ of Variance $=45.9$.

The results of the showed that overall inertia of two-dimensional solution is 0.993 (99\% variance). The figure also showed that the people who attained information about the pandemic from television/news have high hesitancy level and they are not vaccinated. On the contrary, the respondents who collected information about the pandemic from newspapers have medium level hesitancy and they are vaccinated against COVID-19. The low hesitancy and family are not associated with any selected variables. that the masses can be controlled by injection vaccination was not agreed by most of the respondents (Disagree $=30 \%$ and Strongly Disagree $=17.8 \%$ ). Similarly, most of the respondents was also not in

\section{CONCLUSION}

The study concluded that the males are more vaccinated than females and the prevalence of vaccination is a little higher in rural areas than urban areas of South Punjab. The study also concluded that the people who have been acquiring information about the COVID-19 pandemic from 
television/news have higher level of vaccination hesitancy and they are not vaccinated. On the contrary, the people who have been attaining information from newspapers have medium level of vaccination hesitancy and they are vaccinated.

The study suggests launching a campaign at national news channels to reduce impact of the unconfirmed information propagated bout the pandemic and vaccination. The fake news especially on social media are also needed to be dealt with because there are bulk of materials which promoting conspiracy theories about the deleterious effects of the vaccination despite the fact that the confirmed cases of the COVID-19 and deaths are continuously increasing.

Acknowledgement: The author acknowledges the funding of the University of Okara for this research project.

\section{REFERENCES}

Eguia, H., Vinciarelli, F., Bosque-Prous, M., Kristensen, T., \& Saigí-Rubió, F. (2021). Spain's Hesitation at the Gates of a COVID-19 Vaccine. Vaccines, 9(2), 170.

Guillon, M., \& Kergall, P. (2021). Factors associated with COVID-19 vaccination intentions and attitudes in France. Public health, 198, 200-207.

Holeva, V., Parlapani, E., Nikopoulou, V. A., Nouskas, I., \& Diakogiannis, I. (2021). COVID-19 vaccine hesitancy in a sample of Greek adults. Psychology, Health \& Medicine, 1-7.

Khan, Y. H., Mallhi, T. H., Alotaibi, N. H., Alzarea, A. I., Alanazi, A. S., Tanveer, N., \& Hashmi, F. K. (2020). Threat of COVID-19 vaccine hesitancy in Pakistan: the need for measures to neutralize misleading narratives. The American journal of tropical medicine and hygiene, 103(2), 603.

Lucia, V. C., Kelekar, A., \& Afonso, N. M. (2020). COVID-19 vaccine hesitancy among medical students. Journal of Public Health (Oxford, England).

Perveen, S., Akram, M., Nasar, A., Arshad-Ayaz, A., \& Naseem, A. (2021). Vaccination-hesitancy and vaccination-inequality as challenges in Pakistan's COVID-19 response. Journal of community psychology.

Pummerer, L., Böhm, R., Lilleholt, L., Winter, K., Zettler, I., \& Sassenberg, K. (2020). Conspiracy theories and their societal effects during the COVID-19 pandemic. Social Psychological and Personality Science, 19485506211000217.

Rhodes, M. E., Sundstrom, B., Ritter, E., McKeever, B. W., \& McKeever, R. (2020). Preparing for A COVID-19 vaccine: A mixed methods study of vaccine hesitant parents. Journal of Health Communication, 25(10), 831-837.

Saied, S. M., Saied, E. M., Kabbash, I. A., \& Abdo, S. A. E. F. (2021). Vaccine hesitancy: Beliefs and barriers associated with COVID-19 vaccination among Egyptian medical students. Journal of medical virology, 93(7), 4280-4291.

Solís Arce, J. S., Warren, S. S., Meriggi, N. F., Scacco, A., McMurry, N., Voors, M., ... \& Omer, S. B. (2021). COVID-19 vaccine acceptance and hesitancy in low-and middle-income countries. Nature medicine, 27(8), 1385-1394. 